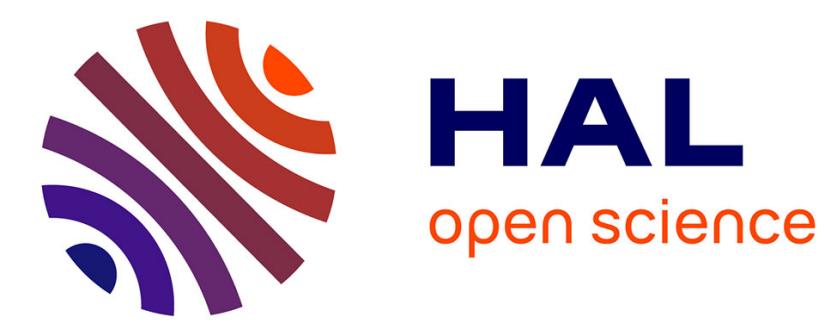

\title{
2D MODELLING OF SILICON CHEMICAL VAPOR DEPOSITION IN AN IMPINGING JET REACTOR
}

\author{
Y. Wang, C. Chaussavoine, F. Teyssandier
}

\section{To cite this version:}

Y. Wang, C. Chaussavoine, F. Teyssandier. 2D MODELLING OF SILICON CHEMICAL VAPOR DEPOSITION IN AN IMPINGING JET REACTOR. Journal de Physique IV Proceedings, 1991, 02 (C2), pp.C2-39-C2-46. 10.1051/jp4:1991204 . jpa-00249771

\section{HAL Id: jpa-00249771 https://hal.science/jpa-00249771}

Submitted on 1 Jan 1991

HAL is a multi-disciplinary open access archive for the deposit and dissemination of scientific research documents, whether they are published or not. The documents may come from teaching and research institutions in France or abroad, or from public or private research centers.
L'archive ouverte pluridisciplinaire HAL, est destinée au dépôt et à la diffusion de documents scientifiques de niveau recherche, publiés ou non, émanant des établissements d'enseignement et de recherche français ou étrangers, des laboratoires publics ou privés. 
2D MODELLING OF SILICON CHEMICAL VAPOR DEPOSITION IN AN IMPINGING JET REACTOR

\author{
Y. WANG, C. CHAUSSAVOINE and F. TEYSSANDIER \\ CNRS, Institut de science et de Génie des Matériaux et \\ Procédés, Université, Avenue de villeneuve, F-66860 Perpignan \\ cedex, France
}

\begin{abstract}
Numerical 2D modelling of silicon deposition in steady state conditions from a $\mathrm{SiH}_{4}-\mathrm{H}_{2}$ initial gas mixture is undertaken in an impinging jet configuration. Variable physical properties and dilute reactants in the carrier gas are assumed. The influence on both the deposition rate and the silicon deposition profile of transport phenomena and chemical reactions in the gas phase are studied. Homogeneous and heterogeneous reactions are considered with three chemical species resulting from silane dissociation in a $\mathrm{H}_{2}$ carrier gas: $\mathrm{SiH}_{4}$, $\mathrm{SiH}_{2}$ and $\mathrm{Si}_{2} \mathrm{H}_{6}$. Comparison is made between calculations achieved under kinetic control or thermodynamic equilibrium.
\end{abstract}

\title{
INTRODUCTION
}

Axisymmetric reactors such as rotating disk, impinging jet or stagnation point flow are attractive systems with well defined flow fields [1]. For a wide range of deposition parameters and within a limited radial distance the two-dimensional description can be assumed as one-dimensional. The surface of the substrate around the stagnation point is an equally accessible surface to mass transfer and leads to coatings of uniform thickness. The primary causes of failure of the 1D treatment are thermal recirculation and edge effects [2].

In the impinging jet system the reactant gas mixture flows through a cylindrical nozzle perpendicular to the heated substrate surface. This CVD configuration was first investigated to study the growth of tungsten layers on a Mo-plate from a WF6-H2 initial gas mixture [3]. Various shapes of deposition profile are observed with respect to temperature and total pressure, but the presence of an area of uniform deposition thickness is confirmed. This feature is also demonstrated in the case of boron deposition from $\mathrm{BCl}_{3}$ and $\mathrm{H}_{2}$ [4]. The deposition mechanisms are in this case deduced from a model based on diffusion of chemical species through the boundary layer. The impinging jet has also been discussed for the case of silicon deposition [5].

Such a reactor, which can be modelled in a rather straightforward way, is well adapted to check chemical kinetics [1]. 1D numerical treatment in the case of boron deposition allowed for the first time the consideration of homogeneous reactions [6]. The calculated concentration profiles establish that the concept of a unique diffusion layer thickness is no longer valid in this case. The same model has also been applied to the deposition of boron carbide [7] and the concentration profiles in the gas phase calculated under kinetic control are compared with the local equilibrium assumption. 
In this paper a $2 \mathrm{D}$ numerical model is applied to silicon deposition for an impinging jet geometry.

\section{MODEL DESCRIPTION}

The impinging jet geometry used for our calculation is described in detail elsewhere [8]. Our system is composed of an upward facing nozzle of radius Ro at a distance $\mathrm{H}$ from the substrate so that $H / R o=8.0$. The flow is subject to the gravitational field. The substrate surface is heated at a constant temperature on a disk of radius 10.Ro. Beyond this radius the temperature decreases linearly to $298 \mathrm{~K}$ at a distance 21 . Ro from the axis. Heat is transferred from the substrate to the gas phase by convection and diffusion. Gasphase irradiation, viscous energy dissipation and the Dufour effect are neglected as is usual in a conventional CVD process. Though thermal diffusion (Soret diffusion) may have an appreciable influence on deposition rates [9-10], it has not been considered in this study. Variable physical properties were taken into account, but due to the low concentration of chemical species in the hydrogen carrier gas, the dilution approximation to the diffusion equations was applied and the reaction enthalpies were neglected.

The set of differential equations, subject to the specified boundary conditions, is solved by the finite volume technique with a conventional rectangular grid provided with a variable step near the substrate surface and in the vicinity of the axis.

The 27 homogeneous reactions published in the literature for the $\mathrm{Si}-\mathrm{H}$ system [11] were not considered here, but only two of them according to previous modelling of silicon CVD in a horizontal reactor [12]:

$$
\mathrm{SiH}_{4} \rightleftharpoons \mathrm{SiH}_{2}+\mathrm{H}_{2} \text { and } \mathrm{Si}_{2} \mathrm{H}_{6} \rightleftharpoons \mathrm{SiH}_{4}+\mathrm{SiH}_{2}
$$

We also assumed the surface reaction probability of $\mathrm{SiH}_{2}$ and $\mathrm{Si}_{2} \mathrm{H}_{6}$ equal to one. The expression giving the reaction probability of silane as a function of temperature comes from reference [11].

\section{RESULTS}

In most applications uniform thickness of the coating is required and this means a uniform access of the chemical species to the surface. In order to fulfil this condition it is necessary to prevent the formation of recirculations in the flow field. Numerical models allow the optimization of the flow streamlines with respect to the influence of deposition parameters or geometry of the reactor [13]. But even in the absence of recirculations the uniformity of the growth rate can be altered by a modification of the precursor species resulting from homogeneous reactions. Figures 1 and 2 compare the isotherms, the streamlines and the mass-fraction contour for $\mathrm{SiH}_{4}, \mathrm{SiH}_{2}$ and $\mathrm{Si}_{2} \mathrm{H} 6$ at two temperatures $(973.15 \mathrm{~K}$ and $1683.15 \mathrm{~K})$.

We first observe that the isotherms and the streamlines are only slightly modified by the strong increase of the temperature indicating that forced convection is much more important than free convection. The high speed of the gas mixture impinging on the surface is also responsible for the steep thermal gradient near the substrate surface in front of the nozzle.

The slowest homogeneous reaction is the initial silane decomposition. Silylene which results from this first reaction is very rapidly transformed into disilane. We can then interpret these curves in the following way: immediately on leaving the nozzle silane spreads out by a convective-diffusion process, and as soon as the temperature is high enough it starts to decompose into silylene which in turn recombines quasi-immediately 
with silane to form disilane. As already mentioned for the same chemical system in a horizontal CVD reactor [12] silylene is confined in a sharp boundary layer above the surface because this species is kinetically formed and thermodynamically stable at high temperature (see figure 3a further). The maximum concentration for both silylene and disilane is observed in an annular domain near the substrate. The diameter of these domains decreases with increasing temperature. As already observed, the residence time of the species is only slightly modified with temperature which means that formation of $\mathrm{SiH}_{2}$ and $\mathrm{Si}_{2} \mathrm{H}_{6}$ will happen closer to the axis when the temperature is raised.

We now turn to the lateral variation of the deposit. The three gaseous species contribute to the silicon growth rate but the ratio between silane and silylene (or disilane) surface reaction efficiency is $3.10^{-6}$ at $973 \mathrm{~K}$ and $2.10^{-4}$ at $1683 \mathrm{~K}$. These values account for the preponderant contribution of $\mathrm{Si}_{2} \mathrm{H}_{6}$ at intermediate temperatures even at low concentrations compared with $\mathrm{SiH}_{4}$. On the deposition profiles presented in figure $\mathbf{3 a}$ two lateral secondary peaks are observed at intermediate temperatures and must be associated with the $\mathrm{Si}_{2} \mathrm{H}_{6}$ (and to a lesser extent with $\mathrm{SiH}_{2}$ ) maxima already mentioned. These peaks are no longer present at high temperatures due to a decrease in the diameter corresponding to the annular maximum for $\mathrm{Si}_{2} \mathrm{H}_{6}$, an increased stability of $\mathrm{SiH}_{2}$ at the expense of $\mathrm{Si}_{2} \mathrm{H}_{6}$, and because of the depletion of the gas phase flowing along the substrate surface.

The thermodynamic calculations of the overall equilibria give valuable information on the behavior of complex chemical systems [14]. Minimisation programs have been used since the beginning of the seventies and it is interesting to check the validity of such calculations, taking into account the homogeneous reactions and the mass transfer of the reactants towards the surface. Local thermodynamic calculations were performed assuming infinite reaction rate in the gas phase but the same sticking coefficient for surface reactions in order to focus on homogeneous reactions. Figures $4 a$ and $4 \mathrm{~b}$ show the variation of the gas phase composition along the axis between the nozzle and the substrate at low and high temperature in the case of both kinetic control and local thermodynamic equilibrium. At 973K (figure 4a) the concentration of intermediate species is at least three orders of magnitude lower than the initial silane which can be considered as constant along the axis, leading to a high supersaturation at the interface. This phenomenon is clearly seen in figure $1 \mathrm{~b}$ where the mass-fraction contours at the interface with the substrate are perpendicular to the surface. The silylene concentration curves in figures $\mathbf{4 a - b}$ are not affected by the hypothesis about the controlling process and this species is always at equilibrium. In accordance with thermodynamic equilibrium a low amount of $\mathrm{Si}_{2} \mathrm{H}_{6}$ is already present at the entrance of the tube.

The influence of temperature is illustrated in figure $\mathbf{3 b}$ where the contributing fraction of each precursor at the centre of the substrate is plotted. As already mentioned $\mathrm{SiH}_{2}$ is at equilibrium at all temperatures, but the contributing species are completely out of equilibrium below $1200 \mathrm{~K}$. Si2 $\mathrm{H}_{6}$ which is the thermodynamically stable species at low temperature is completely absent because of the low kinetics of silane decomposition.

Under local equilibrium the deposition rate is only limited by the mass transfer of the reactants towards the surface providing the highest growth rate for a given set of operating conditions. Accordingly the deposition rate calculated at the centre of the substrate (figure $4 c$ ) is always lower under kinetic limitations. The equilibrium 
conditions are reached at temperatures over $1400 \mathrm{~K}$ when $\mathrm{SiH}_{2}$ is the preponderant species at the interface and reacts with a probability of one at the surface.

The silicon deposition yield for the reactor calculated as the ratio of the mass of silicon sent through the nozzle to the mass deposited on the whole surface is plotted in figure 3d. The curve for the kinetically controlled process is very similar to the contribution of silylene which is the main precursor of silicon over $1100 \mathrm{~K}$ (figure $4 \mathrm{a}$ ). The yield is better than $60 \%$ above $1400 \mathrm{~K}$.

\section{CONCLUSION}

The model predictions have shown the influence of homogeneous reactions on the deposition process. These reactions modify the nature and concentration of species involved in surface reactions. Even with slow kinetic at low temperatures they may be responsible for deposition thickness inhomogeneity.

\section{REFERENCES}

\section{$11 /$ Jensen K.F.}

Proc. of the IX Intern. Conf. on CVD, Van Den Brekel C.H.J.,Cullen

G.W.,Blocher J.M.,Rai-Choudhury P.,Robinson Mc.D.(Eds) Cincinatti USA, (1984) 3.

12/ Houtman C., Graves D.B., Jensen K.F., J.Electrochem.Soc., 133,5 (1986) 961.

13/ Wahl G., Batzies P.,

Proc. of the IV Intern. Conf. on CVD, Wakefield G.F. , Blocher J.M. (Eds), Boston USA, (1973) 425.

14/ Vandenbulcke L., Vuillard G.,

J.Electrochem.Soc., 124,12 (1977) 1931.

15/ Hitchman M.L.,

Proc. of the IV Euro. Conf. on CVD, Bloem J. , Verspui G. , Wolff L.R. (Eds), Eindhoven THE NETHERLANDS, (1983) 167.

16/ Michaelidis M., Pollard R.,

J.Electrochem.Soc., 131,4 (1984) 860.

17/ Rebenne H., Pollard R.,

J.Am.Ceram.Soc., 70,12 (1987) 907.

18/ Wang Y., Chaussavoine C., Teyssandier F.,to be published in J.Cryst.Growth.

19/ Jenkinson J.P., Pollard R., J.Electrochem.Soc., 131,12 (1984) 2911.

/10/ Wahl G., Schmaderer F., Huber R., Weber R., Proc. of the X Intern. Conf. on CVD, Cullen G.W., Blocher J.M. (Eds), Honolulu USA (1987) 42.

111/ Coltrin M.E., Kee R.J., Miller J.A., J.Electrochem.Soc., 133,6 (1986) 1206.

/12/ Moffat H.K., Jensen K.F., J.Electrochem.Soc., 135,2 (1988) 459.

113/ Fotiadis D.I., Kieda S., Jensen K.F., J.Cryst.Growth, 102 (1990) 441.

/14/ Bernard C.,

Proc. of the VIII Intern. Conf. on CVD, Wahl G. , Blocher J.M. ,Vuillard G.E. (Eds), Paris FRANCE, (1981) 3. 


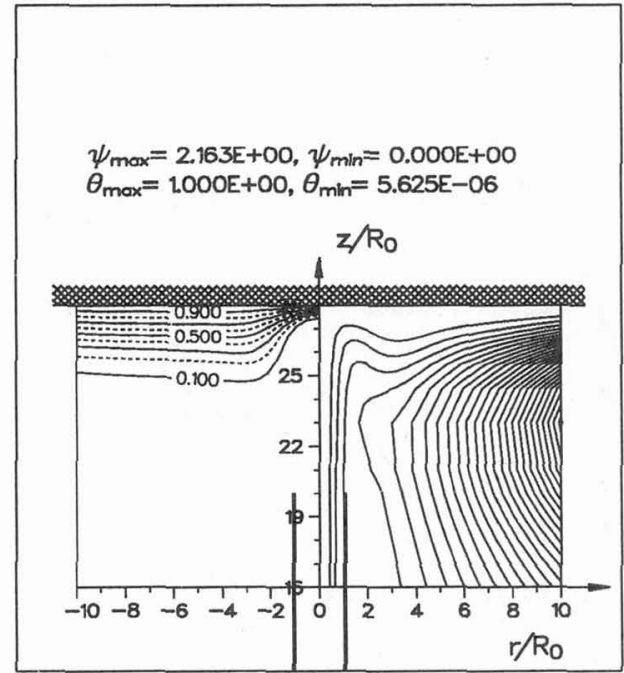

(a)

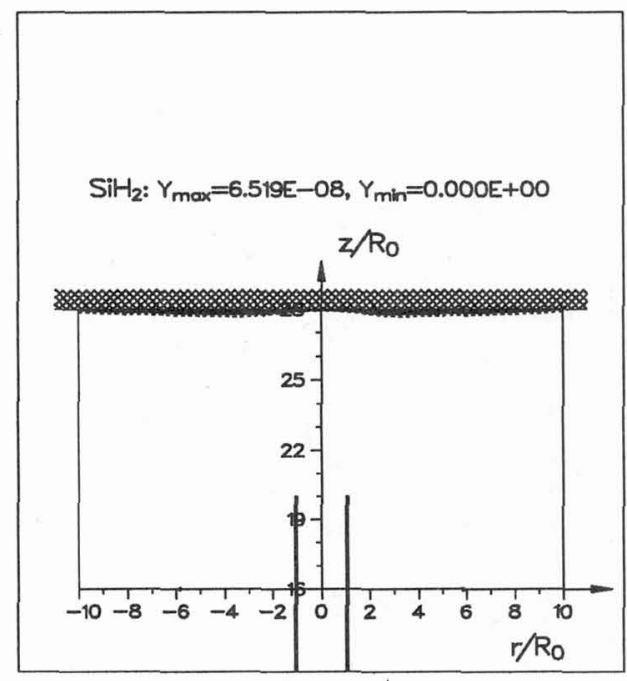

(c)

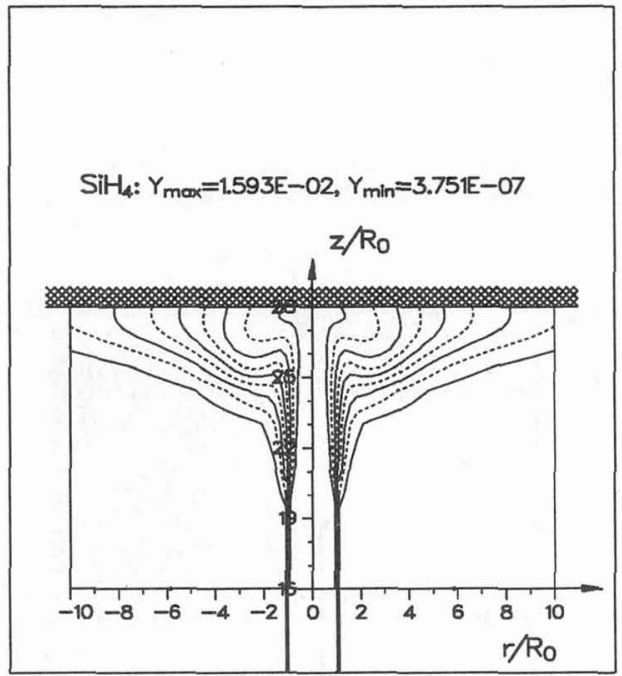

(b)

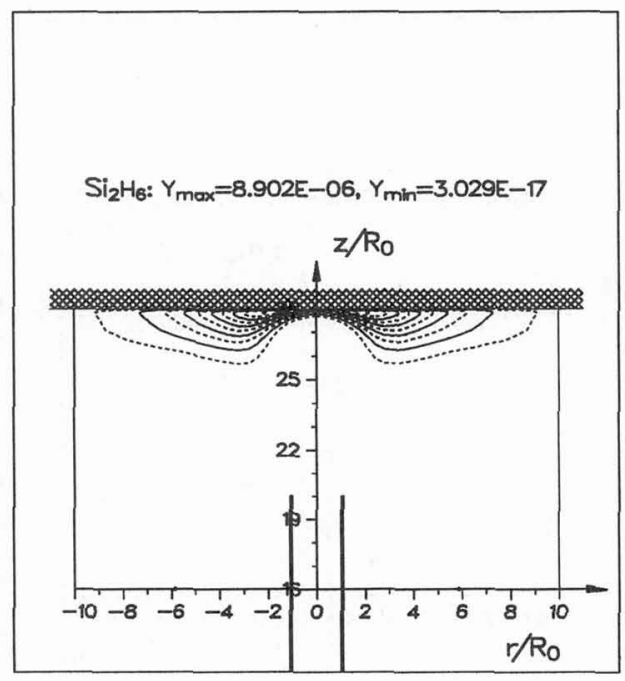

(d)

Figure 1: $T_{s}=973.15 \mathrm{~K}$,

$R_{0}=0.01 \mathrm{~m}, H / R_{0}=8.0, T_{0}=298.15 \mathrm{~K}, P_{0}=1.0 \mathrm{~atm}$, $V_{\max 0}=1.0 \mathrm{~m} / \mathrm{s}, \mathrm{SiH}_{4}$ initial mass fraction $=0.01593$

a) Stream lines (right hand side) and isotherms (left hand side) b),c),d) Mass fraction contours from $Y_{\min }$ to $Y_{\max }$,
b) $\mathrm{SiH}_{4}$;
c) $\mathrm{SiH}_{2}$;
d) $\mathrm{Si}_{2} \mathrm{H}_{6}$ step $\left(Y_{\max }-Y_{\min }\right) / 10$ 


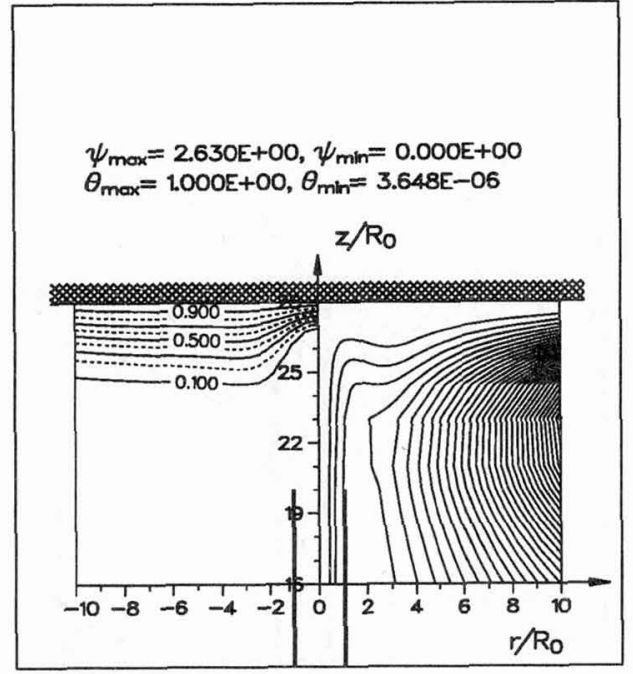

(a)

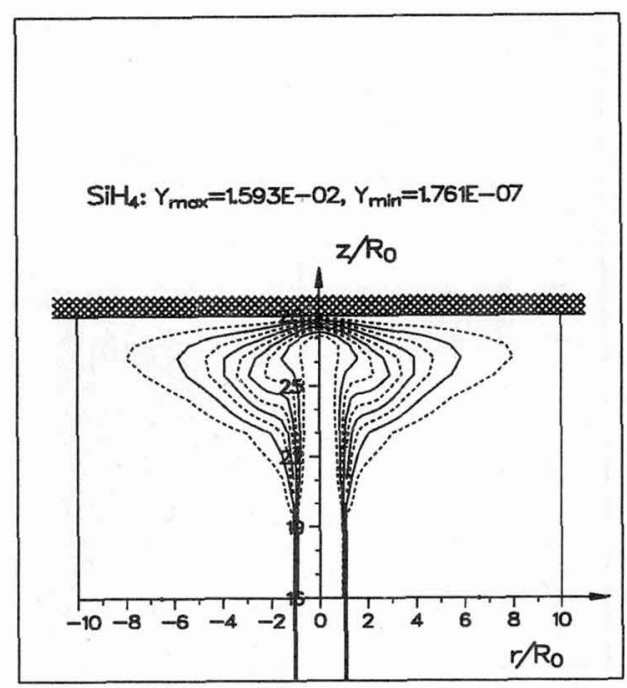

(b)

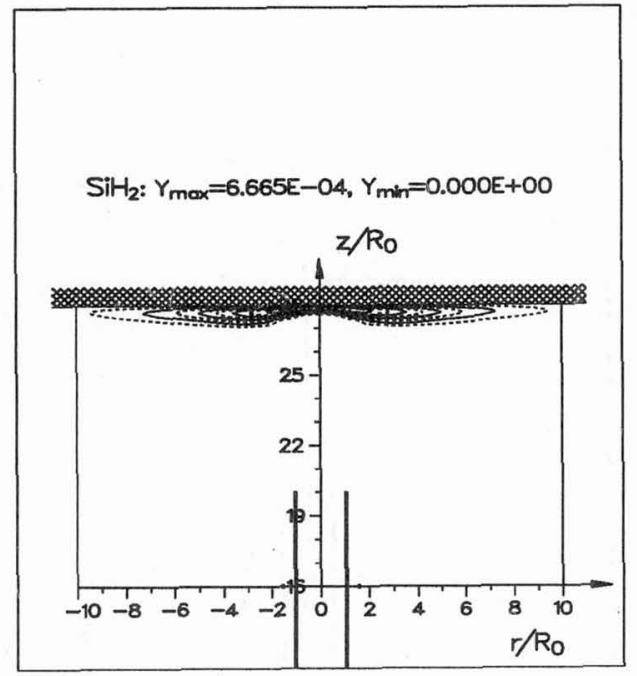

(c)

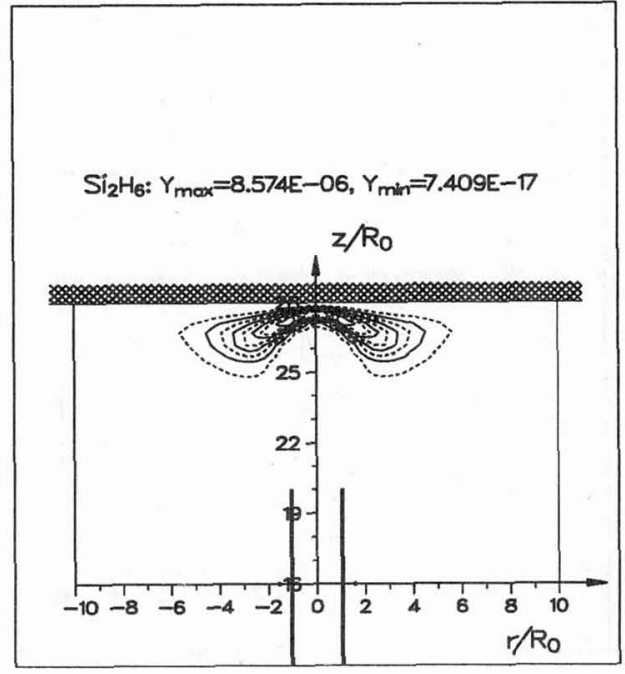

(d)

Figure 2: $T_{s}=1683.15 \mathrm{~K}$,

$R_{0}=0.01 \mathrm{~m}, \mathrm{H} / \mathrm{R}_{0}=8.0, T_{0}=298.15 \mathrm{~K}, P_{0}=1.0 \mathrm{~atm}$,

$V_{\max 0}=1.0 \mathrm{~m} / \mathrm{s}, \mathrm{SiH}_{4}$ initial mass fraction $=0.01593$

a) Stream lines (right hand side) and isotherms (left hand side)

b),c),d) Mass fraction contours from $Y_{\min }$ to $Y_{\text {max }}$, step $\left(Y_{\max }-Y_{\min }\right) / 10$
b) $\mathrm{SiH}_{4}$
c) $\mathrm{SiH}_{2}$
d) $\mathrm{Si}_{2} \mathrm{H}_{6}$ 


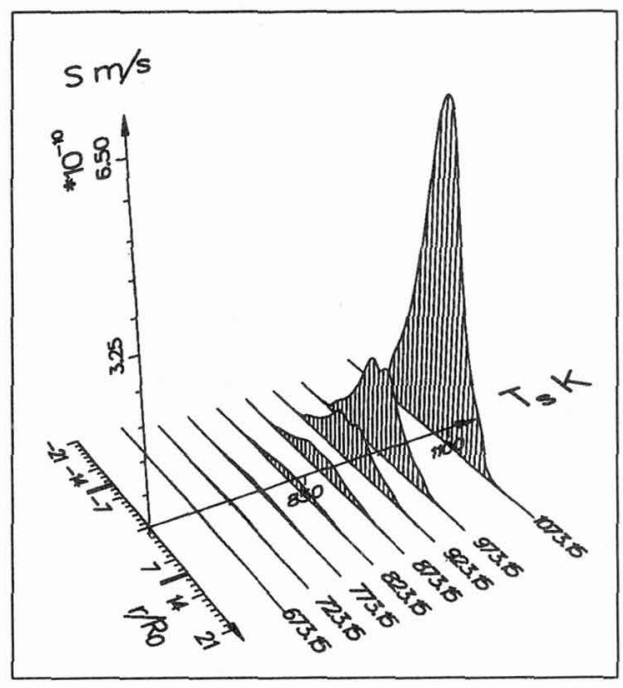

(a)

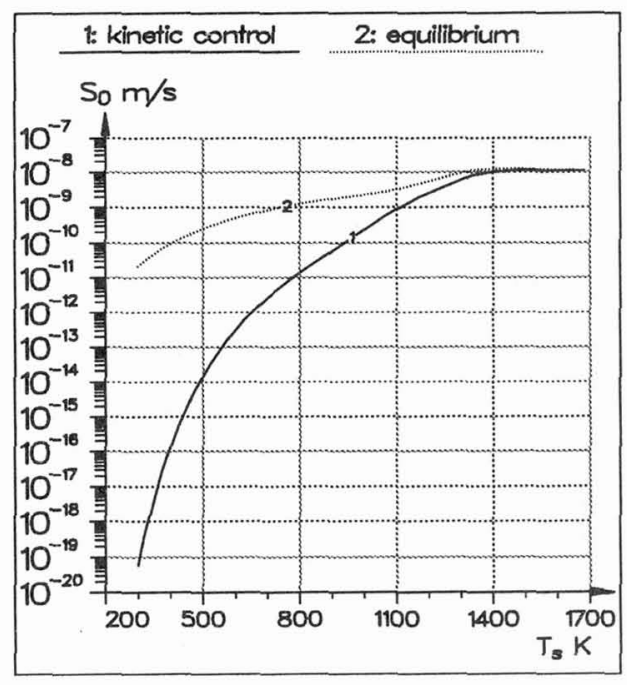

(c)

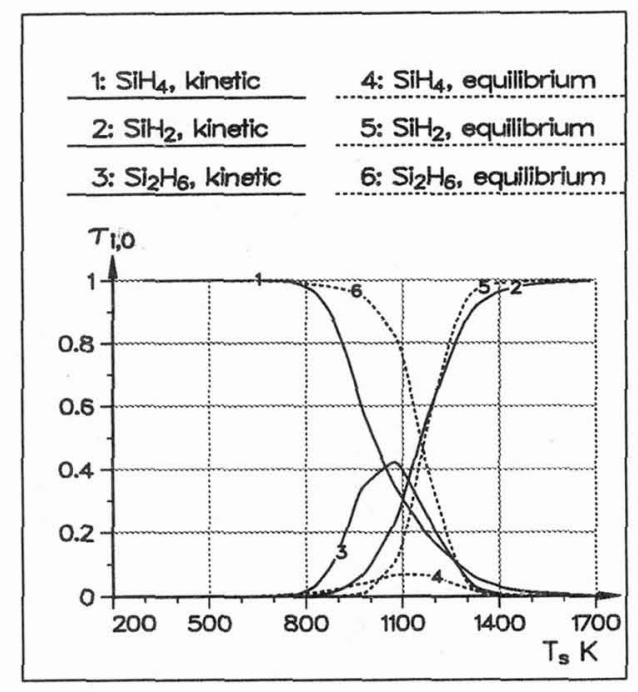

(b)

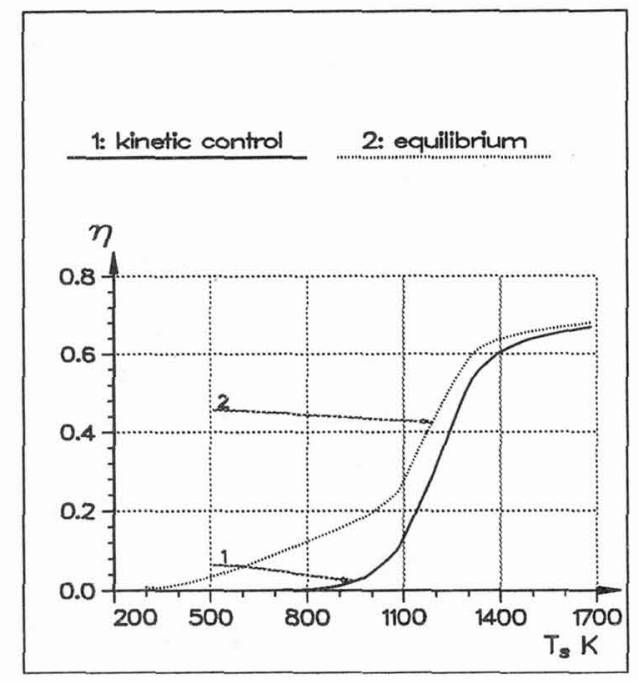

(d)

Figure $3: R_{0}=0.01 \mathrm{~m}, H / R_{0}=8.0, T_{0}=298.15 \mathrm{~K}, P_{0}=1.0 \mathrm{~atm}$, $V_{\max 0}=1.0 \mathrm{~m} / \mathrm{s}, \mathrm{SiH}_{4}$ initial mass fraction $=0.01593$

a) $S$ : deposition rate profile as a function of the substrate temperature

b) $\tau_{1,0}$ : contribution of species $i$ at the stagnation point

c) $S_{0}$ : deposition rate at the stagnation point

d) $\eta$ : reactor yield 


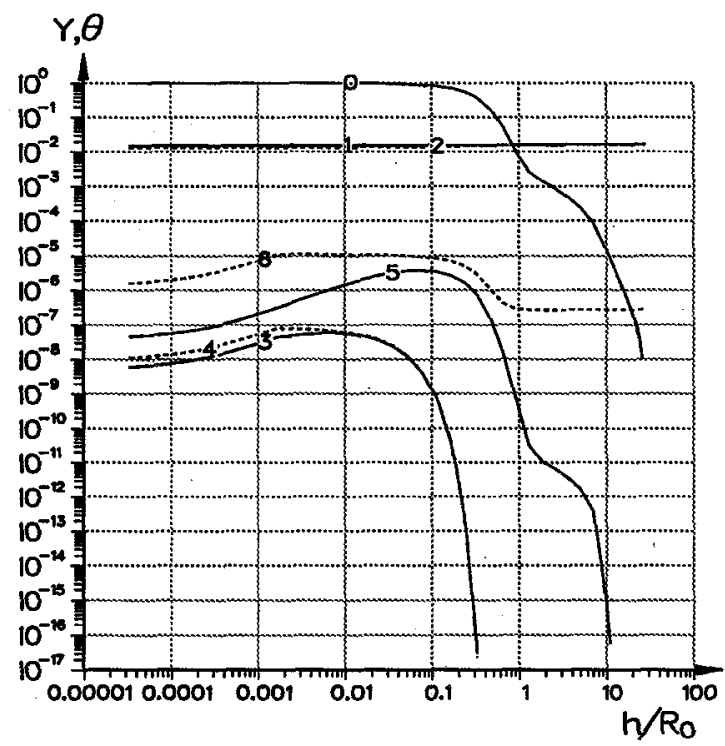

(a): $T_{s}=973.15 \mathrm{~K}$

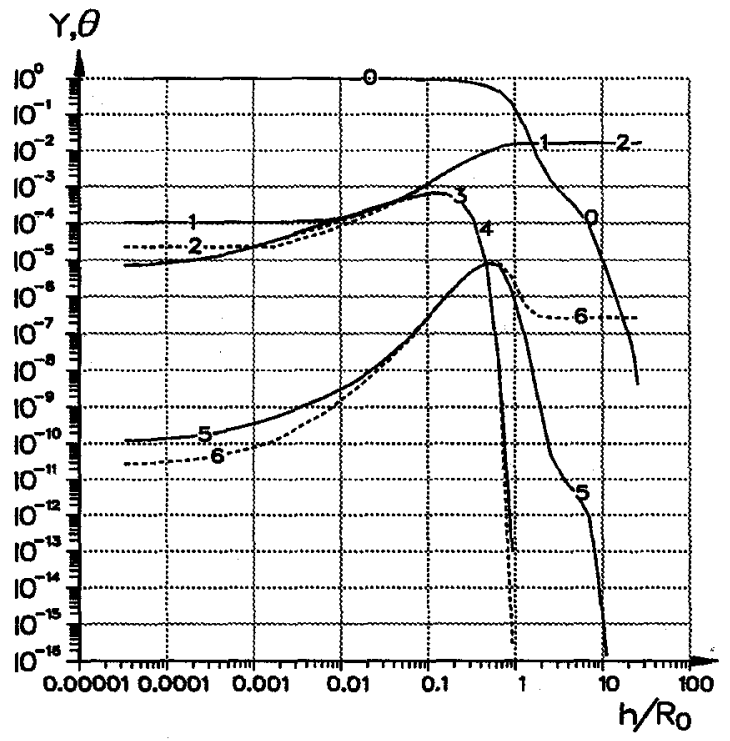

(b): $T_{s}=1683.15 \mathrm{~K}$

Figure $4: R_{0}=0.01 \mathrm{~m}, H / R_{0}=8.0, T_{0}=298.15 \mathrm{~K}, P_{0}=1.0 \mathrm{~atm}$, $V_{\max 0}=1.0 \mathrm{~m} / \mathrm{s}, \mathrm{SiH}_{4}$ initial mass fraction $=0.01593$

0 : adimensional temperature $\theta$

$1: \mathrm{SiH}_{4}$ mass fraction, kinetic control

$2: \mathrm{SiH}_{4}$ mass fraction, thermodynamic equilibrium

$3: \mathrm{SiH}_{2}$ mass fraction, kinetic control

4 : $\mathrm{SiH}_{2}$ mass fraction, thermodynamic equilibrium

$5: \mathrm{Si}_{2} \mathrm{H}_{6}$ mass fraction, kinetic control

$6: \mathrm{Si}_{2} \mathrm{H}_{6}$ mass fraction, thermodynamic equilibrium 